๑0 Entomologica Fennica. 3 November 1997

\title{
Wing dimorphism of the water strider Limnogonus franciscanus (Stål) (Heteroptera: Gerridae) in a seasonal tropical climate
}

\author{
Matti Nummelin
}

\begin{abstract}
Nummelin, M. 1997: Wing dimorphism of the water strider Limnogonus franciscanus (Stål) (Heteroptera: Gerridae) in a seasonal tropical climate. Entomol. Fennica 8: 167-170.

The seasonal occurrence of wing morphs of Limnogonus franciscanus was studied in a mangrove swamp by taking monthly samples during nineteen months. Altogether 428 males and 413 females were collected. The percentage of winged individuals remained constant at ca. $3.2 \%$ throughout the study period. There were no differences between sexes in the proportions of winged and wingless morphs. The frequency of gravid females peaked during the rainy periods.
\end{abstract}

M. Nummelin, Division of Environmental Biology, Department of Ecology and Systematics, P.O. Box 7 (Unionink. 44), FIN-00014 University of Helsinki, Finland, e-mail Matti.Nummelin@Helsinki.FI

Received 5 February 1996, accepted 10 April 1996

\section{Introduction}

The wing-length patterns of tropical water striders in constantly breeding populations are not well studied. Selvanayagam and Rao (1986) showed seasonal changes in the wing morphs of Gerris spinolae in South Western India (G. spinolae Lethierry \& Severin is a synonym of Aquarius adelaidis (Dohrn), see Andersen 1990). The proportion of winged individuals increased from the dry season minimum of ca. $20 \%$ to almost $100 \%$ just after monsoon rains. The plentiful rains in seasonal tropical areas generate many water bodies suitable for water strider breeding. It could be expected that water striders would take advantage of such new water bodies by producing longwinged individuals capable of migrating to new habitats during the rainy period. On the other hand, intraspecific competition in a constantly breeding population is expected to favor individuals with rapid reproduction, especially during a period when new living space appears owing to the rise in water level. This will be promoted, if the flying apparatus is not developed (e.g. Spence 1989). This study reports how a constantly breeding population of a dimorphic water strider species responses to a seasonally changing environment.

The species studied here, $L$. franciscanus, is common and widely distributed in the West Indies, Central America and Mexico, extending north into Florida and the southern parts of Texas (Smith 1988). Based on notes about wing dimorphism in L. franciscanus (Hynes 1948, Cobben 1960, De Kort-Gommers \& Nieser 1969, Nieser \& AlkinsKoo 1991), it seems that the species is dimorphic in almost all sites and the proportion of longwinged and short-winged individuals varies among sites.

The rainfall pattern at my study site in Barbados, resembles to some extent the monsoon climate in SW India (cf. Gerris spinolae above). Approximately $75 \%$ of the average 1200 -mm yearly rain, falls in the seven months from June to mid- 
December. The driest months are February to April (Rouse 1966). Temporary pools, lasting some months, are abundant during the rainy season. The yearly temperature maximum occurs during the rainy period. The day length varies about 2 hours over a year.

In temperate zones it is common to find seasonal variation in the proportions of water strider wing morphs. The variation seems to be regulated by environmental cues like photoperiod and/or temperature (e.g., Vepsäläinen 1978, Spence 1989, Spence \& Andersen 1994). Vepsäläinen (1978) suggested that in Europe increasing day length indicates early summer and acts as a switch to produce short-winged individuals which will produce a second generation during the same summer. According to Vepsäläinen (1978), low temperatures indicate stability of the site and also favor the production of short-winged individuals.

The primary question in this study is: Are there seasonal changes in the proportions of wing

Table 1. Numbers of winged (LW) and wingless (SW) morphs of Limnogonus franciscanus in monthly samples collected in 1992-93 from Graeme Hall Mangrove Swamp in Barbados. Rainfall data is from Rockley ( $1 \mathrm{~km}$ West from Graeme Hall, Barbados Meteorological Institute). ? = no sampling.

\begin{tabular}{|c|c|c|c|c|c|c|}
\hline & \multicolumn{2}{|c|}{ Males } & \multicolumn{2}{|c|}{ Females } & \multirow[b]{2}{*}{ Gravid } & \multirow[b]{2}{*}{ Rain, $\mathrm{mm}$} \\
\hline & LW & SW & LW & SW & & \\
\hline \multicolumn{7}{|l|}{1992} \\
\hline May & 1 & 19 & 0 & 21 & 12 & 178.0 \\
\hline June & 0 & 32 & 1 & 32 & 21 & 134.2 \\
\hline July & 2 & 26 & 0 & 19 & 8 & 47.5 \\
\hline Aug. & 0 & 26 & 1 & 26 & 13 & 116.1 \\
\hline Sept. & 0 & 11 & 1 & 11 & 1 & 80.9 \\
\hline Oct. & 1 & 28 & 1 & 19 & 1 & 14.2 \\
\hline Nov. & 3 & 19 & 2 & 14 & 1 & 107.3 \\
\hline Dec. & 0 & 19 & 0 & 18 & 1 & 30.9 \\
\hline \multicolumn{7}{|l|}{1993} \\
\hline Jan. & 0 & 13 & 3 & 16 & 2 & 57.4 \\
\hline Feb. & $?$ & $?$ & $?$ & $?$ & $?$ & 28.8 \\
\hline Mar. & 0 & 19 & 0 & 22 & 2 & 50.1 \\
\hline Apr. & 0 & 14 & 0 & 17 & 2 & 19.5 \\
\hline May & 0 & 11 & 0 & 16 & 1 & 72.7 \\
\hline June & 0 & 18 & 1 & 17 & 4 & 67.0 \\
\hline July & 1 & 27 & 2 & 27 & 10 & 53.1 \\
\hline Aug. & 0 & 35 & 0 & 39 & 13 & 31.5 \\
\hline Sept. & 0 & 15 & 1 & 17 & 14 & 88.1 \\
\hline Oct. & 3 & 41 & 0 & 29 & 15 & 130.8 \\
\hline Nov. & 2 & 42 & 1 & 39 & 2 & 90.4 \\
\hline
\end{tabular}

morphs in the continuously-breeding, tropical population of $L$. franciscanus and are the possible changes related to rainfall or day length? This paper represents the first detailed assessment of wing dimorphism in a tropical, constantly breeding water strider species.

\section{Material and methods}

I studied a population of $L$. franciscanus, consisting of several thousand individuals, throughout a year by taking monthly samples over 19 months from a mangrove swamp in Barbados, West Indies. The site, Graeme Hall Swamp, is the only one harboring a large population of $L$. franciscanus on the island. The swamp (ca. 35 ha) is an area of pond, marsh, and mangrove forest located near the south coast of Barbados $\left(59^{\circ} 35^{\circ} \mathrm{W}, 13^{\circ} 03^{\prime} \mathrm{N}\right)$ in a densely populated area. It is the last surviving mangrove forest in Barbados and has a long history of human use.

I collected water striders with a pond net while walking slowly along a trail approximately $0.5 \mathrm{~km}$ long which crossed the swamp, separating marsh and mangrove forest. The trail was under water during the rainy seasons and during the dry seasons there was water on both sides of the trail, especially in a ditch on the mangrove side. I attempted to catch all adults encountered. Females having swollen abdomen were considered to be gravid.

\section{Results}

According to my results, wing patterns in $L$. franciscanus in Barbados includes just two morphs. All short-winged individuals were apterous. Winged individuals are capable of flying and I found occasional individuals outside the study area on water pools unsuitable for reproduction like cisterns or city fountains.

Of the 428 males and 413 females collected, $3.1 \%$ of the males and $3.5 \%$ of the females were long-winged (Table 1). Due to the low number of long-winged individuals, no differences were found in the proportions of wing morphs between the rainy (Jul.-Dec.) and the dry (Jan.-May) parts of the year or between the long-day (Apr.-Sep.) and the short-day (Oct.-Mar.) parts. The proportion of long-winged individuals did not correlate significantly with rainfall (Spearman Rank Correlation $r_{s}=0.19$ ). The proportion of gravid females correlated significantly with rainfall $\left(r_{s}=\right.$ $0.474, p=0.05, n=18$ ), indicating higher breed- 
ing activity during rainy periods (Table 1 ). At the end of the study period, 30 fifth instar and 12 fourth instar larvae from Graeme Hall Swamp were checked for their wing-pads. No larvae with distinct wing pads were found. However, fifth instar larvae with distinct wing-pads were found outside the study area in temporary habitats occupied by winged adults.

\section{Discussion}

Seasonal changes could not be detected in the wing morph proportions of the L. franciscanus population in Graeme Hall Swamp. However, it seems that there is a population level response to seasonal changes in the environment. Reproductive peaks are timed to the late dry season and early rainy season.

Andersen (1993) used a phylogenic approach to analyze the evolution of wing polymorphism in water striders. He suggests that the most ancestral forms of wing patterns in water striders are permanent winglessness (SW) or permanent dimorphism. In permanent dimorphism, all SW adults develop from fifth instar nymphs with reduced wing-pads. According to Andersen (1993), more developed evolutionary stages in water strider wing morphs are seasonal dimorphism and monomorphic long-wingedness (LW). He also suggests that once the short-winged adult morph has been lost it is never regained in the original form where the flightless morph develops from nymphs with reduced wing-pads. Instead, shortwinged adults may develop from nymphs with distinct wing-pads.

Observations in this study suggest that $L$. franciscanus in Graeme Hall Swamp belongs to the most ancestral permanent dimorphic class of water strider wing patterns. No seasonality could be found although its environment changes seasonally with respect to rainfall, day length and temperature. Also all short-winged individuals seem to develop from fifth instar nymphs with reduced wing-pads, fitting the prediction of Andersen (1993).

It seems that there is no strong selection toward a winged morph in L. franciscanus in Barbados. Maybe migrating winged morphs on a fairly dry island cannot find enough suitable habi- tats isolated from the permanent swamp to breed. During the rains, the water rises also on the Graeme Hall Swamp providing more space to breed. It is possible that short-winged morphs, as faster breeders (see e.g. Spence 1989), can utilize more efficiently the seasonally appearing new areas in the swamp. If there are any environmental switches to short- or long-wing morphs in this species, it seems that under Barbados conditions they are not active.

Acknowledgements. N. M. Andersen kindly determined the species, he as well D. Fairbairn, J. Spence, K. Vepsäläinen and $\mathrm{M}$. Weale made valuable comments on the earlier versions of this paper.

\section{References}

Andersen, N. M. 1990: Phylogeny and taxonomy of water striders, genus Aquarius Schellenberg (Insecta, Hemiptera, Gerridae), with a new species from Australia. Steenstrupia 16: 37-81.

Andersen, N. M. 1993: The evolution of wing polymorphism in water striders (Gerridae): a phylogenic approach. Oikos 67: 433-443.

Cobben, R. H. 1960: The Heteroptera of the Netherlands Antilles. I: Gerridae, Veliidae, Mesoveliidae (Water Striders). - Studies of Curacao and other Caribbean islands 50: 1-34.

De Kort-Gommers, M. \& Nieser, N. 1969: Records of Antillean water-striders (Heteroptera). - Studies of Curacao and other Caribbean islands 112: 72-87.

Hynes, H. B. N. 1948: Notes on the aquatic HemipteraHeteroptera of Trinidad and Tobago, B.W.I., with a description of a new species Martarega B. White (Notonectiidae). - Trans. R. Entomol. Soc. London 10: 341-360.

Nieser, N. \& Alkins-Koo, M. 1991: The water bugs of Trinidad and Tobago. - Occasional Paper No. 9., Zoology Department, University of West Indies, St. Augustine, Trinidad.

Rouse, W. R. 1966: The moisture balance of Barbados and its influence on sugar cane yield. - McGill University Climatological Publication 1A: 1-154.

Selvanayagam, M. \& Rao, T. K. R. 1986: Wing polymorphism in five species of Gerrids from South India (Heteroptera: Gerridae). - J. of Current Bioscience 3: 6171.

Smith, C. L. 1988: Family Gerridae Leach, 1815. The water striders. - In: Henry, T. J. \& Froeschner, E. J. (eds.), Catalog of the Heteroptera, or true bugs, of Canada and continental United States: 140-151. Brill, Leiden, Netherlands.

Spence, J. R. 1989: The habitat templet and life history strategies of pond skaters (Heteroptera: Gerridae): repro- 
ductive potential, phenology, and wing dimorphism. — Can. J. Zool. 67: 2432-2447.

Spence, J. R. \& Andersen, N. M. 1994: Biology of water striders: Interactions between systematics and ecology. - Annu. Rev. Entomol. 39: 101-128.

Vepsäläinen, K. 1974: Determination of wing-length and diapause in waterstriders (Gerris, Heteroptera). Hereditas 77: 163-176.

Vepsäläinen, K. 1978: Wing dimorphism and diapause in Gerris: Determination and adaptive significance. - In: Dingle, H. (ed.), Evolution of insect migration and diapause: 218-253. Springer-Verlag, New York, U.S.A. 